\title{
Traditional versus hypertextual index in an on-line course on Oscillation and Wave Physics
}

\begin{tabular}{|c|c|}
\hline Journal: & Computer Applications in Engineering Education \\
\hline Manuscript ID & Draft \\
\hline Wiley - Manuscript type: & Special Issue Article \\
\hline Date Submitted by the Author: & $\mathrm{n} / \mathrm{a}$ \\
\hline Complete List of Authors: & $\begin{array}{l}\text { Pejuan, Arcadi; Universitat Politècnica de Catalunya, Physics } \\
\text { López, Víctor; Universitat Autònoma de Barcelona, CRECIM (Center for } \\
\text { Research in Science and Mathematics Education) }\end{array}$ \\
\hline Keywords: & $\begin{array}{l}\text { hypertext, concept map, on-line course design, blended representations, } \\
\text { self-directed learning }\end{array}$ \\
\hline 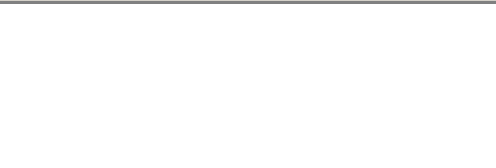 & $\begin{array}{l}\text { SCHOLARONE }^{\text {s' }} \\
\text { Manuscripts }^{\text {Manus }}\end{array}$ \\
\hline \multicolumn{2}{|c|}{$\begin{array}{l}\text { This is the pre-peer reviewed version of the following article: } \\
\text { Pejuan, A, and López V. Traditional versus hypertextual index } \\
\text { in an on line course on Oscillation and Wave Physics, } \\
\text { Comput Appl Eng Educ } 26 \text { (2018), 1470-1480, } \\
\text { DOI 10.1002/cae.21984, which has been published in final form } \\
\text { at http://onlinelibrary.wiley.com/doi/10.1002/cae.21984/full . }\end{array}$} \\
\hline
\end{tabular}


Traditional versus hypertextual index in an on-line course on Oscillation and Wave Physics

\begin{abstract}
We describe an on-line course on Oscillation and Wave Physics (https://ocw.upc.edu/webs/42254/Acustica_EN/), also used within a first-year subject on General Physics in our engineering college. Especially, we describe a new hypertextual index, based on a concept map, and the students' response to this index as compared to a traditional index.
\end{abstract}

Keywords: hypertext; concept map; on-line course design; blended representations; self-directed learning.

\title{
Introduction
}

We implemented an on-line course on Oscillation and Wave Physics intended as an introduction to acoustics, since it specifically addresses the wave nature of sound. This on-line course was also used in the framework of the compulsory first-year subject on General Physics in our engineering college. It is freely accessible as Open Course Ware of the first author's university under the web address https://ocw.upc.edu/webs/42254/Acustica_EN/index.htm in English, with links to Spanish and Catalan versions.

In the implementation of the on-line course, we took account of the need to face prior ideas or misconceptions and to conform to the current knowledge about effective writing for digital media. In addition, the on-line course has been provided with two alternative types of index for accessing the different items: a traditional linear index, and an hypertextual index based on a concept map. 
The objective of this article is:

- to describe the main features of the on-line course as learning environment, specially the two types of index, and

- to report on the students' response to the hypertextual index in comparison to the traditional one.

No previous implementation of a hypertextual index for a physics learning web site is known to us. This is the reason for our interest in studying the students' response.

\section{Rationale for the Design of the On-Line Course - Resulting Main Features}

Concerning the form, the on-line course web site was designed taking the known rules for building effective on-line courseware into account, including the use of hypertext whenever appropriate [1,2]. Particularly, the physics contents were divided into conveniently short web pages, so that, whenever possible, the main text fits the computer screen. In addition, a course unit should contain the main ideas and means to access more information on the content, instead of too many details resulting in the same students' level of achievement but with a significantly longer duration of the preparation [3]. According to the last quoted author, another essential design principle is the chapter ordering of the contents. This led to the introduction of a traditional sequential index or table of contents, which should provide both an overall view and an access to the many web pages through the corresponding links (Figure 1).

[Insert Figure 1 about here]

Concerning the contents, the on-line course web site was also designed under the viewpoint of the conceptual change pedagogies [4-6], which also aim to face prior ideas or misconceptions, about sound in our case [7]. 
The problem of misconceptions about sound has been addressed repeatedly even at college or university level $[8,9]$. At this level, the main misconceptions are related to the sound nature and the sound propagation model, because of considering sound caused by air or medium particles advancing in the space, instead of the oscillation of the air or medium particles which propagates to the neighboring particles [10].

As a way to face this kind of misconceptions, some published remedial approaches have been implemented in our on-line course by means of multimedia resources right from the first web page. The first approach has been the use of bridging analogies in the form of blended representations, given the high efficiency reported by [11-14]. Some examples of blended representations are the graphic and mathematical descriptions of oscillations (Figure 2) and sound wave propagation (Figure 3). Other multimedia resources used are short own-produced videos of hands-on experiments, e.g. about resonance (Figure 4), and embedded applets taken from the web, which meet established evaluation criteria [15-17].

[Insert Figure 2, 3 and 4 about here]

An efficient complementary remedial approach consists of practical activities of ongoing self-assessment [18], which is also applied in our on-line course by means of problem solving (with hints and results) and multiple-choice questions.

Another resource of the conceptual change pedagogies is the use of concept maps, also used to remedy misconceptions $[19,20]$. Concept maps are graphical tools for organizing and representing knowledge. They include concepts, usually enclosed in boxes, and relationships between concepts represented by connecting lines. Words on each line, referred to as linking words or linking phrases, specify the relationship 
between the two concepts. The concepts are represented in a hierarchical structure, with the most general concepts at the top of the map and the more specific concepts arranged hierarchically below [21]. Experimental results show that concept maps are effective and useful for teaching concepts and increasing the students' level of factual knowledge in spite of some difficulties [22-25]. Concept maps are also useful as assessment tool for conceptual understanding in different knowledge areas [26-28].

This suggested the possibility of giving the on-line course the structure of a fully hypertextual environment on the basis of a concept map about Oscillatory and Wave Physics for our engineering students. The linking phrases between nodes were implemented as guiding questions.

This concept map was translated into a hypertextual index or table of contents (Figure 5 , with fully expanded index), where every concept map node corresponds to a theory item, i.e. a web page. The extension of the index can be adjusted by the user at will, according to the desired hierarchical level, clicking on the yellow cases with a plus or minus sign (for expanding or contracting, respectively).

[Insert Figure 5 about here]

Hypertexts are known to have some advantages as learning environments. They allow the reader to develop a non-linear interaction with the content [29], including ways of navigating the content [30,31]. This interaction can foster a flexible and nevertheless deep learning [32] and increase readers' comprehension skills [33]. Hyperlinks provide a high level of learners' control over the order and selection of information through comprehension decisions [34,35]. A hierarchically structured arrangement helps to understand and to solve problems [36], and to understand the macrostructure 
of the semantic relationships between contents that supports more coherent navigation and promotes the construction of a mental representation of the information structure of hypertexts [37].

\section{Traditional versus Hypertextual Index - Students' Response}

As mentioned in the Introduction, the second objective of this article is to report on the students' response to the hypertextual index in comparison to the traditional one. Specifically:

a) Which advantages and drawbacks do students find in the hypertextual index in comparison with the traditional index? (qualitative comparison)

b) Is there any relationship between the use of one or the other index and the performance in the exams? (quantitative comparison)

\section{Students' Populations}

In a first phase covering four semesters, this on-line course on Oscillation and Wave Physics was an essential part of a wider on-line distance learning course on Acoustics. This part of the on-line course was accessible only through the hypertextual index (Fig. 5). The rest of course syllabus was related to more specialized areas like environmental acoustics, musical acoustics and architectural acoustics, and it was accessible only through a traditional index (similar to Fig. 1). This course was for senior students enrolled in different engineering programs, ranging from Telecommunication to Chemistry. These students, 45 in total, formed the population taken for the above question a). 
Later, in a second phase, this on-line course was used in the framework of the compulsory first-year subject on General Physics in our engineering college, for the topic of Oscillation and Wave Physics. Specifically, it was used as environment for autonomous learning at home previously to the traditional face-to-face teaching in a sort of flipped classroom. So, the students had to learn the theory items scheduled for the corresponding class autonomously in advance to the class, using the on-line course. In the class itself, only unclear concepts were clarified and, especially, the problems and multiple-choice questions proposed in the on-line course itself were solved. Of course, the on-line course was also recommended as a learning support for reviewing the contents after the class and preparing the exam. From all the involved freshmen students, we discarded those who did not even take the exam or who reached less than $10 \%$ of the maximum score, because it could be assumed that they had not worked minimally on the subject. As a result, 207 students in five semesters formed the population taken for question b) (96 in the first three semesters, plus 111 in the following two semesters).

\section{Methodology}

Concerning question a), at the end of each course in the first phase, students were asked to comment one or more aspects taken at will from a list of possible aspects of the on-line course. One of these aspects to comment just if desired was the comparison of the study using the web pages accessible through the hypertextual index with the study of the rest of the course using the web pages accessible through a traditional index. The freedom to comment this particular aspect should avoid that students feel compelled to make any stereotyped comments about such a difference, which probably 
would not reflect their true learning experience. Indeed, only a limited number of students, 21 out of 45, made a comment on this specific aspect. Additionally, some of the comments were taken from the discussions within the working groups formed.

Concerning question b), in the first three semesters of the second phase (96 students), only the traditional index was made available. In contrast, in the two subsequent semesters (111 students), only the hypertextual index was available. Then, we compared the performance in the five final General Physics exams with regard to the topic of Oscillations and Waves as a relevant part of these exams.

As a measure of every student's performance, which we call 'Performance Rate', we have taken the ratio of the sum of scores reached in each multiple-choice question or problem-solving item concerning Oscillations and Waves to the sum of the respective maximum scores. Each problem-solving item had a maximum score of 1, and each right answer to a multiple-choice question had a fixed score of 0.5 (-0.17 if wrong). Nevertheless, here we have taken 0 as score both for unanswered multiple-choice questions and wrong answers.

\section{Results for Question a) - Discussion}

Students as a whole do not clearly show a preference for the one type of index to the detriment of the other one, but they point out their advantages and drawbacks according to their learning experience.

Advantages of the hypertextual index (with students' literal expressions, translated into English):

1) To raise the students' curiosity and therefore their interest for the physics contents: 
The order of the topics was chosen according to my curiosity [...] (Electrical Engineering student).

[...] one can gradually evolve and learn according to one's own taste. In other words, choosing the order of topics by oneself makes it more entertaining, because it is always simpler to learn what one likes just then. (Industrial Engineering student).

The main advantage of the hypertextual system is the alternative "playful" way of studying (discussion in one of the working groups).

2) Efficiency of the guiding questions of the hypertextual index in guiding the student: The criterion [for the order to be followed] was to try to always follow the flow lines, in order to try to move forward in the theory without losing sight (Mechanical Engineering student).

$[\ldots]$ the order I followed was very coherent, thanks to the help of the questions in black [guiding questions] and the flow lines, I must admit (Mechanical Engineering student).

Once I have seen how the synoptic [hypertextual] index was structured, it was easier to choose the order [...], always trying to follow one and the same line of knowledge, without going into items which could be more interesting a priori, but which diverted from a logical line [...]. Once I understood the structure of the synoptic [hypertextual] index, I found it much easier and more pleasant to choose the items to be studied. The method of following a preset order [traditional 
sequential index] makes the task much easier, although it takes away some of its attractiveness when studying the topics (Mechanical Engineering student).

3) Freedom to pursue one's own learning itinerary according to the personal leanings, so that physics becomes less hard or laborious:

The detail that most attracted my attention was the freedom to choose the next item to be studied [...] (IT Engineering student).

$[\ldots]$ it is easier to follow a predetermined index, but it may become harder. It is more autodidactic to follow a synoptic [hypertextual] index, so you are choosing the way according to your needs (Mechanical Engineering student).

$[\ldots]$ in the form of a synoptic chart, it offers more freedom so that one can organize the contents at will or according one's interest (Electrical Engineering student).

4) To learn to avoid any obsession with the order of items, as a convenient attitude in order to learn autonomously:

[Concerning the study of the different contents,] sometimes my impression was that I was not doing it in the right order [...], but afterwards I got used to understand it in a parallel way and not to become obsessed with an allegedly correct order (Telecommunications Engineering student).

It is very constructive to learn in this way, because the doubts arise before the answers (Industrial Engineering student).

Another advantage [or the hypertextual index] is the possibility of rectifying, that is to say, if one has chosen an item and afterwards one is not sure about it, one 
can leave it and choose a more suitable one (discussion in one of the working groups).

Drawbacks of the hypertextual index:

1) Possible poor interpretation of the hierarchical order of items:

We agree about the convenience $[\ldots]$ of indicating somehow which items are the most important $[\ldots]$ and which are minor (discussion in one of the working groups).

2) Possibility of interpreting the guiding questions in an equivocal manner:

The [guiding] questions should be as accurate as possible, allowing [...] to get an idea of the contents [...]. Everyone can interpret this guiding questions in a different way, obtaining a "pleasant" or "unpleasant" result once the content hidden in the item becomes disclosed (Telecommunications Engineering student).

Although [the guiding questions] lead you towards which web page [you want to go], it is not clear enough what will be explained there and which background you need (discussion in one of the working groups).

The help of the introductory questions was limited and, in practice, in order to know the content of an item, we rather tended to have a look at it, because in our opinion, a question can be misread (discussion in another working group).

3) Uncertainty about whether the optimal item order is being followed (with the more or less implicit statement that the order proposed by the lecturer is the optimal one): 
$[\ldots]$ but at the same time it created a sense of insecurity for me about whether the path chosen was the most suitable one (IT Engineering student).

[...] Instead, when we use the second method [traditional index], we are absolutely sure that the topics we address will be within our grasp, because the lecturer has scheduled the topics adequately (discussion in one of the working groups).

[With the traditional index,] the student is assured that he or she will not take the wrong path, but all the pieces will fit together if he or she follows this index and if the author has done his or her work well (discussion in another working group).

4) Possible waste of time when a topic must be left aside, for addressing a previous topic needed:

$[\ldots]$ sometimes you can make a wrong choice and you have to turn to previous topics that would be already studied if you had used the second method [traditional index]. The second method is quicker, because you don't need to search, turning to previous topics, and you have not so many doubts arising (Industrial Engineering student).

For example, to solve problem 7.6 of the item "The decibel", one needs to have seen the item "Sound intensity as a function of distance", but I saw it later [...]. To do some exercises, I had to know the theory that I would see afterwards. [...] It is possible that, in order to understand a concept, one has to have previously 
understood another concept not yet seen (my own experience) [...] (Electronic Engineering student).

$[\ldots]$ it is difficult to deduce from a title what should be done first and what shouldn't. So, I found myself studying topics for which other topics were needed on which I hadn't worked (Electrical Engineering student).

Out of these possible drawbacks, the second one is unavoidable, because of the always limited information that a guiding question can convey, necessarily being a short question. However, these comments must be taken into account in order to put guiding questions which are not purely rhetorical but convey the maximum possible information on the content or approach of an item.

The other drawbacks must be put into perspective, particularly the third one. The learning method using a traditional sequential index will always give a greater sense of security than the hypertextual index, because the freedom of choice very often has the price of uncertainty to a greater or lesser extent. This freedom of choice can be considered as a part of autonomous learning, and therefore, it is considered as a disadvantage by students, together with a greater workload [38]. Students are used to the teacher or lecturer as a provider of subject content who needs to fill the students with knowledge [39,40], and they find it hard to learn and work autonomously, developing their own responsibility for learning in tertiary and lifelong education $[41,42]$. However, self-directed learning throughout a lifetime should take the freedom of choice into account as an important value $[41,43]$. The freedom and choice features provided by new self-directed personalized learning environments should be maintained as a support of the constructivist approach and self-regulation, even while 
sustaining the appropriated level of teacher's or lecturer's control and structural requirements of formal learning [44]. In addition, freedom and choice for learning is one of the factors leading to success or personal change. Indeed, in a study with selfdirected learners [45], personal freedom to learn was rated most important for success and personal transformation, and also choice was a key aspect of using open educational content. Choice or freedom to select the topic is also an essential motivational reason for self-directed informal learning, the freedom to learn being a key factor for its success [46]. Therefore, the perception of uncertainty resulting from the freedom to choose a personal path through the hypertextual index of contents cannot be considered a learning disadvantage with respect to the traditional index.

$\mathrm{Al}$ other drawbacks reported were also taken into account for the final version of the hypertextual index used in the second phase. However, these drawbacks remain unavoidable to some minor degree.

\section{Results for Question b) - Discussion}

As a first result, we found no significant difference between the students' performance rate as a whole using the traditional index and using the hypertextual index, with mean values and $95 \%$ confidence intervals of $0.52 \pm 0.04$ and $0.53 \pm 0.04$, respectively.

However, a closer look at the individual results suggested that each performance rate could depend on the particular aspect of the Oscillations and Wave topic addressed by the corresponding individual multiple-choice question or problem-solving item. Therefore, we established the five subtopics of the Oscillations and Wave topic listed in Table 1. We found no significant difference between using the traditional index and 
the hypertextual one for all subtopics, except for No. 3 and 4 in Table 1, where the respective mean performances and their $95 \%$ confidence intervals are given.

[Insert Table 1 about here]

All performance rates are around 0.5 , after excluding the students with an exam score under $10 \%$ of the maximum, as explained in the Methodology subsection above.

For subtopics 1, 2 and 5, the absence of significant differences in the performance rate can be due to the lack of learning advantages of one type of index over the other one in these subtopics. Indeed, the different issues in these subtopics can be treated in a rather linear way, i.e. with no direct need to consider any relevant interrelationships with issues belonging to other subtopics. In this case, the traditional linear index should not be at a disadvantage compared to the hypertextual index, at least with regard to taking exams.

In contrast, in subtopics 3 and 4 there are cross-linked relationships between different conceptual aspects, and these relationships should be addressed as explicitly as possible for a better understanding. This is obviously the case for the relationship between the wave as a whole and the local oscillations at the different points of a wave propagation medium, and it also applies for the close relationship between the local oscillation energy and the energy propagation in a wave, together with the resulting wave intensity in the case of acoustic waves. Here, the concept map which is behind the hypertextual index was most probably a relevant help for building deeper knowledge concerning these interrelationships, according to the considerations in the Rationale section, based on the literature about concept maps (especially [21-24]). 
Another reason for the absence of significant differences in some performance rates could be the teaching method described in the Students' Populations subsection. Indeed, in the sort of flipped-class approach applied, the autonomous learning using the on-line course was followed by a face-to-face class with complementary activities like clearing up of doubts or problem solving. This can be expected to have evened out the differences to some extent. However, for subtopics 3 and 4, the significant performance differences reveal that the use of the concept map in the form of an hypertextual index has probably led to a deeper assimilation or internalization of the above-mentioned interrelationships between conceptual aspects which could not be reached in the face-to-face class activities, according to the literature quoted above on conceptual maps.

\section{Conclusions}

In a first phase, the on-line course was used with the hypertextual index for the Oscillations and Waves topic as introduction to a wider subject on Acoustics, but using a traditional index for the rest of this subject. As a qualitative student response, we collected the free comments made (if desired) by students on the difference in using each type of index. Students found some advantages of the hypertextual index, e.g. the ability to rise curiosity increasing interest in the physics contents, or the building of a convenient attitude for learning autonomously. In contrast, the drawbacks perceived were e.g. the possible equivocal interpretation of the guiding questions, or the uncertainty about the optimal order of items to be followed.

In the Discussion of these qualitative results, these perceived drawbacks have been put into perspective, as an unavoidable part of a more autonomous and self-directed 
learning in comparison to the externally directed learning through a traditional sequential index, resulting in indirect advantages for a self-directed personalized learning, according to the literature quoted there.

In a second phase, the on-line course was used for the topic of Oscillation and Waves within the first-year subject on General Physics, in a sort of flipped-class approach, where students had to learn the contents autonomously before the face-to-face class. The course version with only the traditional index was available in some of the semesters, while the course version with only the hypertextual index was available in the other semesters. As a quantitative student response, no significant overall performance difference in the exams was observed, if all Oscillations and Waves subtopics as a whole are considered. However, we found a not large but significant difference for two subtopics related to cross-linked relationships between different conceptual aspects, like the relationship between local oscillations at the different points of a wave propagation medium and the wave as a whole, and also between local oscillation energy and energy propagation in a wave, including wave intensity. The lack of a more extensive significant performance difference is compatible with a lack of advantage of one index over the other with regard to taking exams. It can also be explained by some evening-out effect of the complementary face-to-face activities. In contrast, for both above-mentioned subtopics, the significant performance differences can be explained by a deeper internalization of those above-mentioned cross-linked relationships through the concept map underlying the hypertextual index, according to the literature. 


\section{References}

[1] B. Carroll, Writing for Digital Media, Ed. Routledge, 2010.

[2] K. Campbell, E-ffective writing for e-learning environments, Ed. Information Science Publishing, 2004.

[3] O. Istrate, Visual and pedagogical design for eLearning content. eLearning Papers, 17, 1-12 (2009). Online at https://www.academia.edu/3356976/Visual_and_pedagogical_design_of_eLearni ng_content. Accessed September 2017.

[4] T. Coruhlu-Senel, M. Çalik, S. Cepni, Effect of conceptual change pedagogies on students' alternative conceptions of electricity resistance and electricity current, Energy Education Science and Technology - Part B, 4, 141-152 (2012).

[5] S. Er Nas, M. Çalik, S. Cepni, Effect of different conceptual change pedagogies embedded within 5E model on grade 6 students' alternative conceptions of 'heat transfer', Energy Education Science and Technology - Part B, 4, 177-186 (2012).

[6] M. Çalik, A. Kolomuç, Z. Karagölge, The effect of conceptual change pedagogy on students' conceptions of rate of reaction, Journal of Science Education and Technology, 19, 422-433 (2010).

[7] M. Çalik, M. Okur, N. Taylor, A comparison of different conceptual change pedagogies employed within the topic of "sound propagation", Journal of Science Education and Technology, 20, 729-742 (2011).

[8] Z. Hrepic, D.A. Zollman, N.S. Rebello, Identifying students' mental models of sound propagation: the role of conceptual blending in understanding conceptual 
change, Physical Review Special Topics - Physics Education Research, 6, 020114-1-18 (2010).

[9] C. Periago, A. Pejuan, X. Jaén, X. Bohigas, Misconceptions about the propagation of sound waves, European Association for Education in Electrical and Information Engineering Annual Conference, Valencia, Spain, 2009.

[10] A. Pejuan, X. Bohigas, X. Jaén, C. Periago, Misconceptions about sound among engineering students, Journal of Science Education and Technology, 21, 669685 (2012).

[11] N.S. Podolefsky, N.D. Finkelstein, Analogical scaffolding and the learning of abstract ideas in physics: Empirical studies, Physical Review Special Topics Physics Education Research, 3, 020104-1-16 (2007).

[12] S. Yilmaz, A. Eryilmaz, Integrating gender and group differences into bridging strategy, Journal of Science Education and Technology,19, 341-355 (2010).

[13] K. Niebert, S. Marsch, D.F. Treagust, Understanding needs embodiment: A theory-guided reanalysis of the role of metaphors and analogies in understanding science, Science Education, 96, 849-877 (2012).

[14] N.B. Mozzer, R. Justi, Science Teachers' Analogical Reasoning, Research in Science Education, 43, 1689-1713 (2013).

[15] A. Pejuan, X. Bohigas, X. Jaén, An evaluation tool for physics applets, Journal of Technology and Science Education, 6, 36-51 (2015).

[16] E. Debowska, R. Girwidz, T. Greczyło, A. Kohnle, B. Mason, L. Mathelitsch, et al., Report and recommendations on multimedia materials for teaching and 
learning electricity and magnetism, European Journal of Physics, 34, L47-L54 (2013).

[17] G.D. Rey, Seductive details in multimedia messages, Journal of Educational Multimedia and Hypermedia, 20, 283-314 (2011).

[18] E. Engum, A blended classroom plus Students' self-assessment = Visible learning, 7th International Conference of Education, Research and Innovation, ICERI Proceedings, Ed. IATED (Int Assoc Technology Education \& Development), Burjassot-Valencia, Spain, 2014, pp 3924-3924.

[19] N. Dönmez Usta, N. Ültay, Prospective chemistry teachers' abilities of creating concept maps: hydrocarbons example, Journal of Baltic Science Education, 15, 58-67 (2016).

[20] J.D. Novak, Meaningful learning: The essential factor for conceptual change in limited or appropriate propositional hierarchies (liphs) leading to empowerment of learners, Science Education, 86, 548-571 (2002).

[21] J.D. Novak, A.J. Cañas, The Theory Underlying Concept Maps and How to Construct and Use Them, Technical Report IHMC CmapTools 2006-01 Rev 012008, Florida Institute for Human and Machine Cognition, 2008, available at: http://cmap.ihmc.us/Publications/

ResearchPapers/TheoryUnderlyingConceptMaps.pdf. Accessed July 2017.

[22] C. Joseph, D. Conradsson, L.N. Wikmar, M. Rowe, Structured feedback on students' concept maps: the proverbial path to learning?, BMC Medical Education, 17:90 (2017). 
[23] P. Mutodi, B. Chigonga, Concept map as an assessment tool in secondary school mathematics: An analysis of teachers' perspectives, Eurasia Journal of Mathematics, Science \& Technology Education, 12, 2685-2696 (2016).

[24] J.G. Aguiar, P.R.M. Correia, Using concept maps as instructional materials to foster the understanding of the atomic model and matter-energy interaction, Chemistry Education Research and Practice, 17, 756-765 (2016).

[25] J.D. Novak, Concept mapping: A useful tool for science education, Journal of Research in Science Teaching, 10, 923-949 (1990).

[26] S. Eggert, A. Nitsch, W.J. Boone. M. Nückles, S. Bögeholz, Supporting Students' Learning and Socioscientific Reasoning About Climate Change-the Effect of Computer-Based Concept Mapping Scaffolds, Research in Science Education, 47, 137-159 (2017).

[27] M.K. Watson, J. Pelkey, C.R. Noyes, M.O. Rodgers, Assessing conceptual knowledge using three concept map scoring methods, Journal of Engineering Education, 105, 118-146 (2016).

[28] V.S. Kumaran, Towards Formative Assessment of e-Learners Using Concept Map, International Journal of e-Education, e-Business, e-Management and eLearning, 5, 94-104 (2015).

[29] L. Salmerón, T. Baccino, J. Cañas, R. Madrid, I. Fajardo, Do graphical overviews facilitate or hinder comprehension in hypertext?, Computers \& Education, 53, 1308-1319 (2009).

[30] J. Walhout, S. Brand-Gruwel, H. Jarodzka, M. Van Dijk, R. De Groot, P.A. Kirschner, Learning and navigating in hypertext: Navigational support by 
hierarchical menu or tag cloud?, Computers in Human Behavior, 46, 218-227 (2015).

[31] F. Amadieu, L. Salmerón, Digital Knowledge Maps in Education. In D. Ifenthaler and R. Hanewald (Ed.), Digital Knowledge Maps in Education: Technology-Enhanced Support for Teachers and Learners (pp. 41-59). Springer Science+Business Media, 2014.

[32] W. Houghton, Engineering Subject Centre Guide: Learning and Teaching Theory for Engineering Academics, Engineering Subject Centre, Loughborough, 2004.

[33] E. Durukan, Effect of Hypertextual Reading on Academic Success and Comprehension Skills, Educational Research and Reviews, 9, 447-455 (2014).

[34] P. Gerjets, K. Scheiter, M. Opfermann, F.W. Hesse, T.H.S. Eysink, Learning with hypermedia: The influence of representational formats and different levels of learner control on performance and learning behavior, Computers in Human Behavior, 25, 360-370 (2009).

[35] S.A. Sullivan, S. Puntambekar, Learning with digital texts: Exploring the impact of prior domain knowledge and reading comprehension ability on navigation and learning outcomes, Computers in Human Behavior, 50, 299-313 (2015).

[36] D.I. Burin, J.P. Barreyro, G. Saux, N.C. Irrazábal, Navigation and comprehension of digital expository texts: Hypertext structure, previous domain knowledge, and working memory capacity. Electronic Journal of Research in Educational Psychology, 13, 529-550 (2015). 
[37] F. Amadieu, L. Salmerón, J. Cegarra, P. Paubel, J. Lemarié, A. Chevalier, Learning from concept-mapping and hypertext : An eye tracking study. Educational Technology \& Society, 18, 100-112 (2015).

[38] G.V. Espi Lopez, I. Colorado Lluch, M. Jovani Palau, T. Sentandreu Mano, Physiotherapy students' perspectives of the degree and their near academic and professional future, 6th International Conference of Technology, Education and Development (INTED), Valencia, Spain, 2012, pp 6555-6559.

[39] S.T. Cotterill, Tearing up the page: re-thinking the development of effective learning environments in higher education, Innovations in Education and Teaching International, 52, 403-413 (2015).

[40] M. Bagheri, W.Z.W. Ali, M.C. Abdullah, S.M. Daud, Project-based learning as a facilitator to promote students' technology competencies, World Journal on Educational Technology, 5, 207-214 (2013).

[41] M. Havenga, H. de Beer, Project-based learning in consumer sciences: enhancing students' responsibility in learning, Journal of Family Ecology and Consumer Sciences, 44, 58-70 (2016).

[42] O. Adejumo, L. Fakude, N. Linda, Revisiting innovative approaches to teaching and learning in nursing programmes: Educators' experiences with the use of a case-based teaching approach at a nursing school, South African Journal of Higher Education, 28, 1694-1707 (2014).

[43] J. Bessant, A dangerous idea? Freedom, children and the capability approach to education, Critical Studies in Education, 55, 138-153 (2014). 
[44] V.Tomberg, M. Laanpere, T. Ley, P. Normak, Sustaining Teacher Control in a Blog-Based Personal Learning Environment, The International Review of Research in Open and Distributed Learning, 14 (2013). Online at http://www.irrodl.org/index.php/irrodl/rt/printerFriendly/1397/2527. Accessed November 2017.

[45] C.J. Bonk, M.M. Lee, X. Kou, S. Xu, F.R. Sheu, Understanding the self-directed online learning preferences, goals, achievements, and challenges of MIT OpenCourseWare subscribers, Educational Technology \& Society, 18, 349-368 (2015).

[46] D. Song, C.J. Bonk, Motivational factors in self-directed informal learning from online learning resources, Cogent Education, 3: 1205838 (2016). 
Figure 1: Traditional sequential index or table of contents for accessing the different web pages (theory items and self-evaluation activities).

$420 \times 322 \mathrm{~mm}(72 \times 72 \mathrm{DPI})$ 

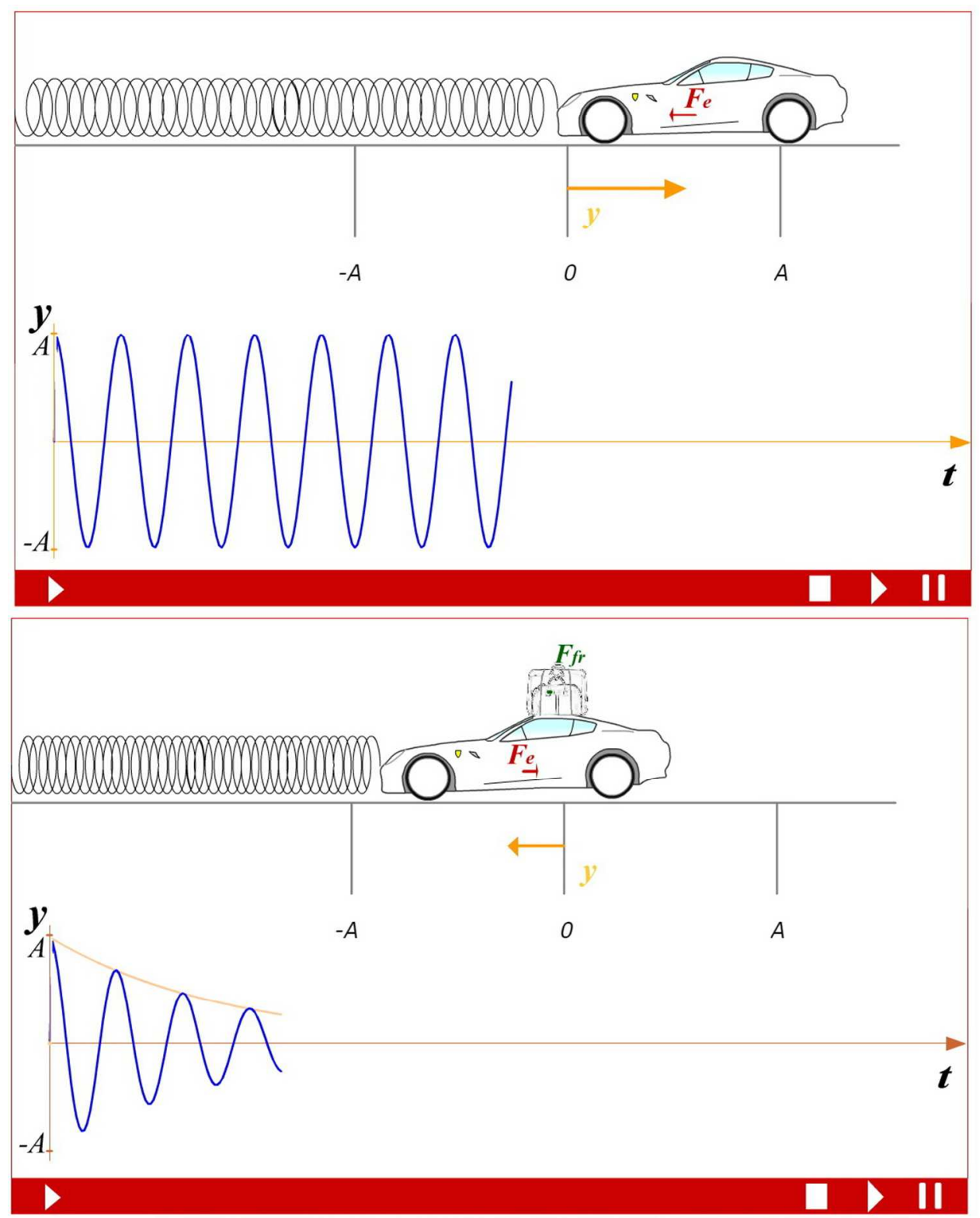

Figure 2: Embedded Adobe Flash animations with blended representations of oscillations (top: simple harmonic motion, bottom: damped oscillation).

$402 \times 502 \mathrm{~mm}(72 \times 72 \mathrm{DPI})$ 


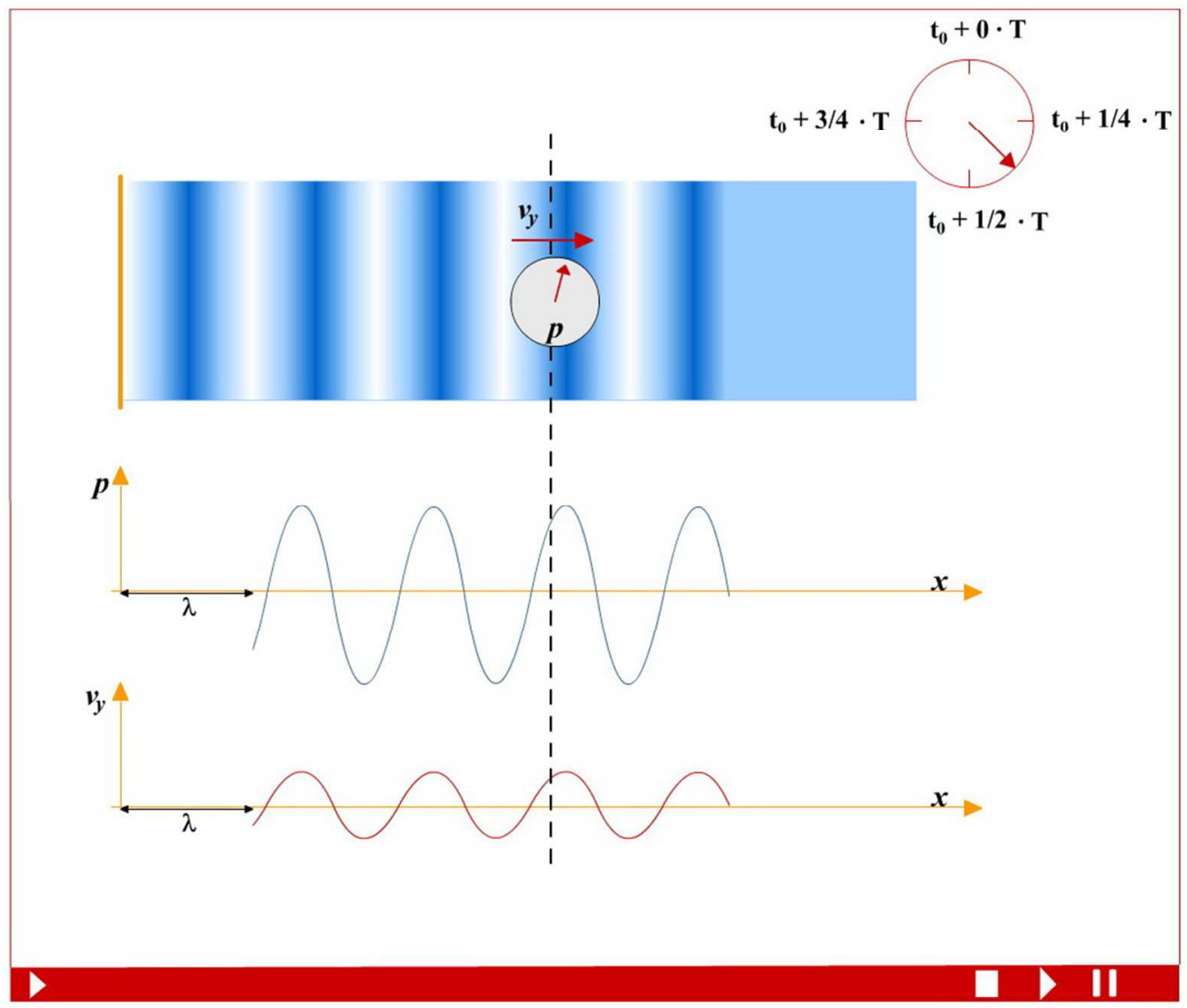

Figure 3: Embedded Adobe Flash animation with a blended representation of a propagating sound wave. $366 \times 310 \mathrm{~mm}(72 \times 72 \mathrm{DPI})$ 


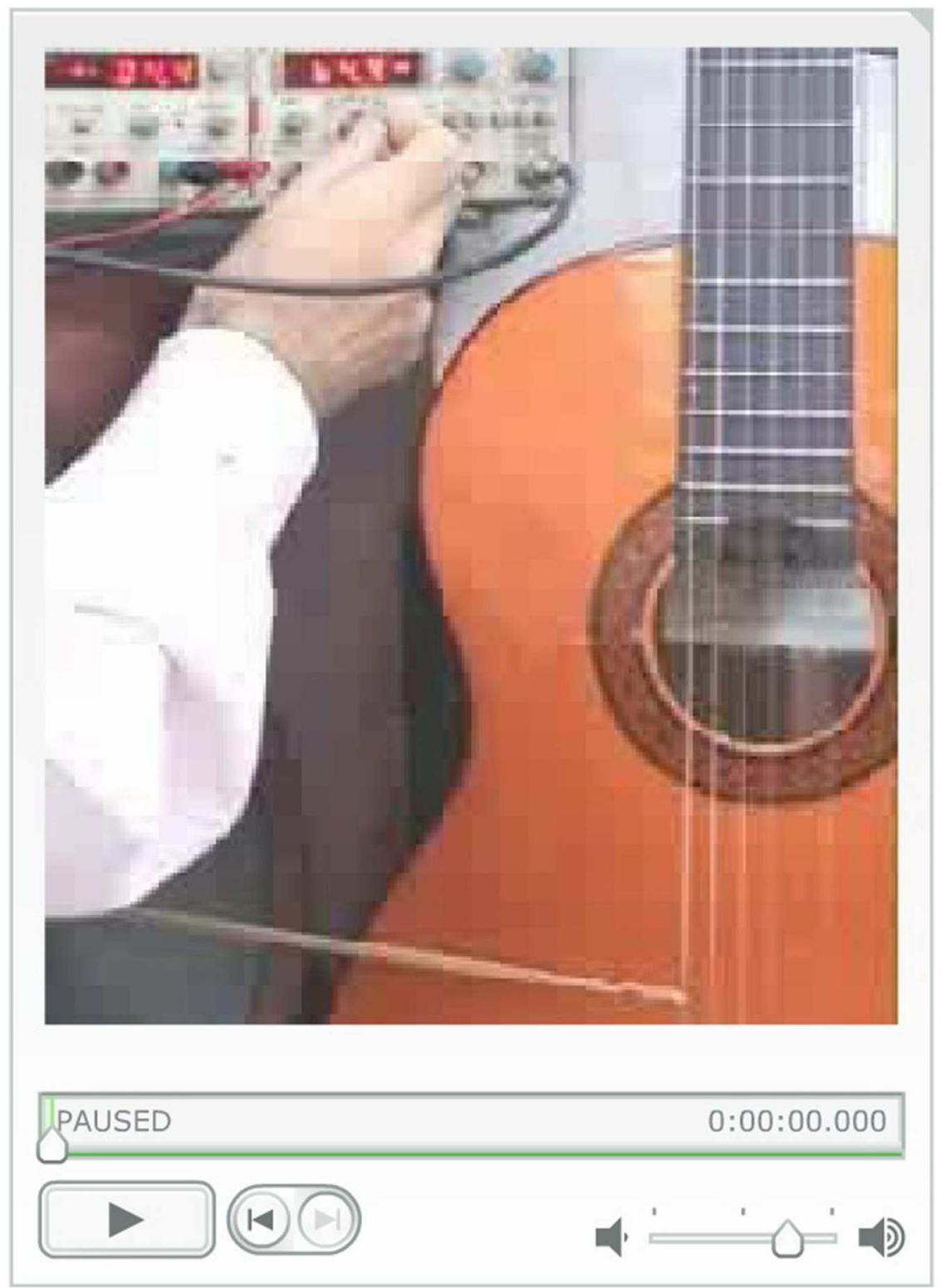

Figure 4: Embedded Adobe Flash video of a hands-on experiment about resonance. $233 \times 320 \mathrm{~mm}(72 \times 72$ DPI $)$ 


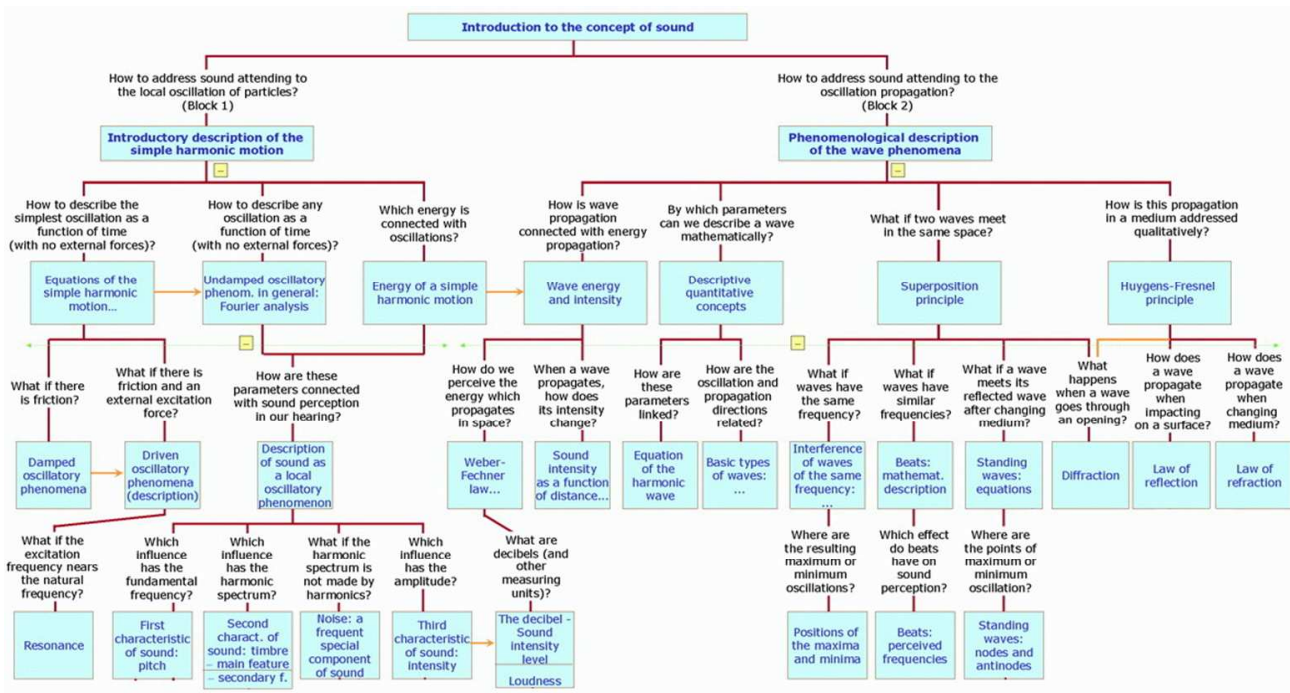

Figure 5: Hypertextual index (fully expanded) based on a concept map, for accessing the different items.

$418 \times 222 \mathrm{~mm}(72 \times 72$ DPI $)$ 
Table 1. Performance Rate (ratio between the sum of scores reached and the sum of maximum scores) for each subtopic of Oscillations and Waves (significant difference in the shaded areas).

\begin{tabular}{|l|c|c|}
\hline Subtopic & \multicolumn{2}{|c|}{ Performance Rate } \\
\cline { 2 - 3 } & with traditional index & with hypertextual index \\
\hline 1. Equation of motion for harmonic oscillations & $0.60 \pm 0.06$ & $0.51 \pm 0.07$ \\
\hline 2. Equation of motion for harmonic waves & $0.5 \pm 0.1$ & $0.53 \pm 0.06$ \\
\hline 3. Relationship between oscillations and waves & $0.50 \pm 0.06$ & $0.63 \pm 0.06$ \\
\hline 4. Energy of oscillations and waves, and sound intensity & $0.45 \pm 0.08$ & $0.60 \pm 0.07$ \\
\hline 5. Superposition of waves & $0.53 \pm 0.04$ & $0.48 \pm 0.09$ \\
\hline
\end{tabular}

